\title{
HOW DO WE KNOW WHAT IS HAPPENING IN WHATSAPP: A CASE STUDY INVESTIGATING PRE-SERVICE TEACHERS' ONLINE ACTIVITY
}

\author{
Nagaletchimee Annamalai \\ School of Distance Education \\ Universiti Sains Malaysia, Malaysia
}

naga@usm.my

Received: 5 February 2018

Revised : 15 June 2018

Accepted: 10 July 2018

\begin{abstract}
Purpose-This study addresses the issue of investigating on how lecturers used WhatsApp in educational context and what are the pre-service teachers' views when WhatsApp is used in teaching and learning activities.
\end{abstract}

Methodology-A qualitative case study was conducted in this study. Two lecturers were interviewed individually to investigate the teaching approach integrated with the use of WhatsApp. Also, 12 pre-service teachers in two focus groups were interviewed to examine their views of using WhatsApp in completing their tasks.

Findings-The lecturers employed blended learning approach and were not keen to entirely conduct their lessons in the online learning environment. The focus group interviews were conducted to bring the data together to generate emerging themes related to positive and negative views of pre-service teachers when they were engaged on WhatsApp for learning activities. The positive themes were related to bite size learning, seamless learning, $21^{\text {st }}$ century learning, WhatsApp as a platform to support learning and as an extended interaction space.

Practical Implications-The study may influence the use of Information Communication and Technology (ICT) tools in education. It also contributes to new ideas and knowledge on how teachers and learners can conceptualize and use ICT. There is a strong case to argue for instructors to be actively involved in interactions to guide students to develop knowledge and ideas. 
Keywords: WhatsApp, online environment, interactions, mobile instant messaging.

\section{INTRODUCTION}

With the increasing amount of Information Communication and Technology (ICT) tools in our daily lives, learners' interactions mediated by technological tools have been a relevant topic of research. More recent development of mobile instant messaging (MIM) with the availability of portable technologies such as smart phones have further increased the interest among researchers and educators to use MIM as an educational stimulus. MIM is often associated with terms like place-based learning (Jones et al., 2013), all time everywhere learning (Norris \& Soloway, 2013) and learning on the move (Sharples, 2013). The success of MIM is closely related to the remarkable growth of a number of applications such as WhatsApp, Telegram, Viber and Line that permit users to send messages efficiently at no cost with more flexible time and space configurations. One of the most popular MIM applications in the market is WhatsApp which is the focus of this study.

Despite the swift spread of WhatsApp application and the rising use of WhatsApp in teaching and learning activities (Aharony, 2015; Appiah, 2016; Fattah, 2015; Man, 2014; Yeboah \& Ewur, 2014), our current understanding of WhatsApp in the Malaysian educational context is limited. Further, the promise of WhatsApp, in the flexibility and the growing collection of positive practices such as collaboration and interactions to construct knowledge remain largely unexplored. Although, a number of studies (Aharony, 2015; Appiah, 2016; Andujar \& Cruz, 2017; Bouhnik \& Deshen, 2014) have acknowledged the positive use of WhatsApp in educational context, a comprehensive and critical review in this regard would be timely to provide the current situation and to discuss the role of WhatsApp in teaching and learning activities. Findings may differ due to geographical location and sociocultural issues. Further, challenges may exist, mainly linked with the quality of WhatsApp as an educational platform. Therefore, it would be vital and informative to investigate the experience of pre-service teachers in using WhatsApp for their learning activities in the teachers' training institutions in Malaysia. 
This study is also in a way significant to the pre-service teachers as it may influence their educational use of technology when they are in schools. According to Korthagen, Loughran \& Russel (2006) studies have reported on 'reality shock', 'praxis shock' or 'transition talk' that pre-service teachers encounter when they enter the profession. In such a situation, a period of consolidation takes place when pre-service teachers are exposed to the integrations of technology in educational context before teachers explore the potential of technology to support their teaching and learning activities (Haydn $\&$ Barton, 2007). This consolidation period may influence the use of technology when they start their career in schools.

Thus, to meaningfully integrate WhatsApp in teaching and learning activities, it is imperative to know the favorable conditions and obstacles for the use of WhatsApp as an educational platform. It is also worthy of further exploration as people are slowly leaving Facebook and began to use WhatsApp as the communication platform (Aharony, 2014). Thus, this study seeks to explore how WhatsApp can enhance traditional teaching and learning activities in higher education and further support their learning outside classroom hours. The objective of this study is to investigate the instructor's use of WhatsApp to design their teaching and learning activities. Further, the study also explores the views of the pre-service teachers in the use of WhatsApp for teaching and learning activities. The following section discusses the qualitative and quantitative research related to the use of WhatsApp in educational context.

\section{LITERATURE REVIEW}

According to the Statistical Portal (2017) there were 700 million of WhatsApp users in January 2015 and 1.2 million active users in the month of January 2017. There has been a rapid escalation in the use of WhatsApp and it has become the largest MIM in the world (Aharony, 2015). One noteworthy matter about the WhatsApp application is that it does not allow communication with people you are not familiar with. Friends of their friends will not be able to share or tag like the Facebook applications. WhatsApp will not be flooded with advertisements and able to inform the senders whether the message has been received and been read by the receiver. Also, it also informs the sender of when the receiver of a message was last online. At the same time, sender can modify the privacy setting by 
not letting those applications available. Obviously, it is a conducive interactive platform which is different from other social networking sites particularly Facebook (Aharony, 2015). Thus, more research is needed to understand on how to prepare and support educators and learners in integrating WhatsApp into the educational context.

It has been relatively a new platform for interactions and collaboration work and its up-to-date features can be utilized wisely for instructors and learners to use it in teaching and learning activities. Realizing this, several studies have tapped into the emerging issue of WhatsApp as an online learning platform. Researchers were motivated to conduct quantitative studies that used statistics to generalize findings and to test theories.

For example, Aharony (2015) explored the factors that influence the students' satisfaction and the time spent on WhatsApp by using Uses and Gratifications(U\&G) approach (Katz, 1959), Big Five Model (Costa \& McCrae, 1992) and Technology Acceptance Model (Davis,1989). Findings reported the use of WhatsApp is mainly because of social interactions and the most dominant characteristic is openness to experience and satisfaction.

Another quantitative study was conducted by Appiah (2016). Appiah (2016) investigated the influence of WhatsApp with 200 university students in Ghana. The study found that students were keen to use WhatsApp for group discussion, network sharing contents and to overcome boredom. The study also importantly pointed out on health related matters such as back pain, eye irritation and headache which eventually affected the students' academic incalculably. This study has advanced to the strengths and weaknesses of WhatsApp; however, less effort has been spent to provide depth and details of the participants' feelings since statistics was used to generalize findings.

Andujar and Cruz (2017) focused on social interactions and measure students' degree of oral development and found that WhatsApp allow students to negotiate meaning, reflect and evaluate their work through interactions and feedback. While the above quantitative studies are needed to reduce and restructure complex problems to a limited number of variables, there are also a number of qualitative research to provide users' needs, preferences, experiences that can actually be ignored in quantitative research. Hani (2014) conducted 
an action research using the WhatsApp group to investigate the significant impact of the voice of the students, vocabulary and word choices among Jordanian students. The study concluded that there was a significant development in vocabulary choice and the voice of the undergraduates. The study was also able to add quality to the students' writing but the author was not able to highlight the students' experiences.

Further, Bouhnik and Deshen (2014) conducted an exploratory study and interviews with teachers who used WhatsApp to interact with students. It was found that WhatsApp was used for "communicating with students; nurturing the social atmosphere; creating dialogue and encouraging sharing among students; and as a learning platform" (p.217). In the local scenario, Man (2014) investigated whether WhatsApp can be used to investigate the potential and drawbacks of WhatsApp in vocabulary learning.

Despite the growing interest in qualitative and quantitative aspects, the integration of WhatsApp in formal education is still at the primary development stage. The initiatives are isolated and gaining momentum, thus more research is needed in this area. Moreover, WhatsApp is relatively new phenomenon in educational context in Malaysia. Thus, this exploratory case study aims to address the gap and extent research on pre-service teachers and the use of WhatsApp. Emanating from this context, the following research questions were formulated for the purpose of this study.

\section{RESEARCH QUESTION}

i. How was WhatsApp used by the lecturers to design their teaching and learning activities?

ii. What were the pre-service teachers' views on the use of WhatsApp in teaching and learning activities?

\section{METHODOLOGY}

The study employed a qualitative case study aimed to gather better understanding of the phenomenon being studied rather than a quantitative method which is often directed by definite answers or examination of certain hypotheses (Cresswell \& Poth, 2017). Two focus group interviews were conducted with 12 pre-service teachers 
from TTCP and TTCI (pseudonym) colleges in Malaysia during the second semester of 2016 academic year. The pre-service teachers were referred as PS1, PS2, PS3 ... and the lecturers were referred as Lecturer 1 and 2. Each group consists of six participants. The two lecturers were also interviewed to investigate their teaching and learning activities. The total number of participants in this study were 14. The researcher used purposive sampling that is made up of participants who were willing to use WhatsApp in their teaching and learning activities. The study involved students from Degree of English program.

Participants signed a consent form and were informed about the nature of the study. The limited number of students is due to the nature of task for interactions and collaboration task. Since the study is an exploratory study and its value is to investigate and rationalize the use of WhatsApp in educational context, the finding of this study is preliminary in setting the guideline to further in-depth and comprehensive research related to WhatsApp.

\section{Research Procedure}

The pre-service teachers received traditional approach of instruction in classroom.

The guideline suggested by Leidner and Jarvenpaa (1995) served as a guiding principal in this study:

i. the use of technology is to redraw the physical boundaries of the classroom

ii. to enable more team work

iii. to allow learning to be a continuous time-dependent process

Focus group interview was used to elicit views of the pre-service teachers. The two lecturers were also interviewed to investigate their teaching approach of the course. The focus group interview for the pre-service teachers were expected to provide a more relax, comfortable and enjoyable discussion as participants are able to share ideas in a non-threatening environment. The interviews were transcribed verbatim and thematic analysis was used to analyze the answers to the research questions.

The themes were analyzed based on Braun and Clarke (2006) thematic analysis which includes five-stage process where the entire data will go through a detail analysis. 
i. becoming familiar with the data: Reading all data for overall comprehension

ii. generating initial codes: initial codes were identified by keywords or/and phrases and sentences that directly indicated ideas, views, concepts and notions of professional development

iii. searching for themes: Similar codes that formed a single theme were put together based on all the initial codes

iv. reviewing themes. The themes were reviewed. Irrelevant themes were either moved or collapsed or segregated or renamed

$v$. defining and naming theme. The themes were named, defined and discussed in the findings 'section by using excerpts, phrases, sentences and paragraphs.

\section{Data Analysis}

The following conventions were used for the presentation of the emerging themes:

- Extracts from the transcripts were not edited for grammar and sentence structures, rather the whole paragraphs were presented intact so that the ideas can be seen in the context

- Within the extracts the key words or phrases illustrate of the emerging themes were circled.

\section{FINDINGS}

The following section discusses on how the lecturers designed their study for the pre-service teachers. The information was gathered from the individual interviews with Lecturer 1 and 2.

\section{Teaching and Learning Approach}

The lecturers were given the flexibility to work on any task related to English Degree program. Lecturer 1 taught Teaching, Reading and Writing in the ESL classroom. She instructed the students to form a group of six students and to interact on aspects related to micro teaching particularly lesson planning, material design, simulated teaching and reflective essays. Students were instructed to do their micro teaching on the fifth week.

Lecturer 2 taught Language Development Course. The lecturer opted for flipped classroom and two other social media to conduct the 
lessons namely WhatsApp and e-mail. Lecturer 2 puts up e-mails and instruct the students to interact on the subject matter. The materials are in the form of documents, slide presentation and videos. The teacher made it compulsory for students to take part in discussion and presentations. On the fifth week and Lecturer 2 gave quiz and exam. Both of the lecturers were not keen to reveal the scores for the course as the results were considered confidential. However, the researcher was also not keen to consider the product of the research and more concerned about the process that pre-service teachers experienced. Both lecturers opted for blended learning approach and the assessment was not done in the online environment. WhatsApp was merely used for the pre-service teachers' discussion related to their tasks.

The next section discusses the emerging themes from the focus group interviews with the pre-service teachers.

\section{Bite Size Learning}

With the use of WhatsApp in educational context, bite size learning is taking place. Bite size learning is an approach where learners acquire certain ideas and knowledge gradually through short modules instead of ideas being presented in chunks or the entire activity at one go. It is found that the teaching and learning activities were broken down to small morsels. For example, one of the pre-service teacher (PS1) explained that: We can actually share audio lessons in our WhatsApp group so that it can help to facilitate learning to the lecture over and over again until we fully understand it". Similarly, another pre-service teacher (PS5) shared the similar experience "we can share links/articles of learning resources in the platform to revise and do extra notes. I don't have to spend more time on searching for resources and notes. I can concentrate on discussions and tutorial tasks". Another pre-service teacher (PS7) explained that "we will post the picture and type our points ...”.

The traditional scenario of an hour lecture or two has changed and given way to the development of bite sized learning. A study conducted by the Rapid Learning institute reported that $94 \%$ of learning and development professionals preferred bite sized learning. Lesson assessed in mobile learning has to be concise and short for students to create learners' experiences because students are not in classroom settings to focus on lengthy modules. This is arguably an advantage for educators as it is hard for learners to focus for 
more than 20 minutes. The learners intended cognitive processing normally exceeds the learner's available cognitive capacity. Therefore, to overcome cognitive overload bite sized learning is deemed appropriate. Bite sized learning allows students to digest intellectually one chunk of ideas or knowledge before moving on to next idea (Stahl et al., 2010). This approach is considered well suited for pre-service teachers as most of them are busy with cocurriculum activities and out of college for practicum and project based learning.

\section{$21^{\text {st }}$ Century Learning}

$21^{\text {st }}$ century skills are another most commonly recurring phrases in the pre-service teachers' interviews. The pre-service teachers realized the approach of using WhatsApp is valuable attempt as they will be able to impart such approaches when they are in schools. The following statements were the typical comment from the interviews:

Her frequent ideas [the instructors] are about $21^{\text {st }}$ century learning, $21^{\text {st }}$ century classroom and flipped classroom method are use in our learning. She also encourages us to give our original ideas so that we can learn from each other (PS2).

A focus on creativity and the use supportive technologies to disseminate ideas and using their own abilities is important in the $21^{\text {st }}$ century learning. For example,

I will use the electronic presentation such as Microsoft PowerPoint to build I-think, Graphic Organizer(GO) for imparting knowledge about a concept more effectively (PS3).

They were also very positive about the need for the use of WhatsApp as an educational platform and highlighted that some of the activities can be applied in their own classrooms after they have completed their training. The pre-service teachers designed activities beyond the traditional classroom approach. This may reflect that WhatsApp is an empowering tool to promote ideas for their teaching activities in future. The pre-service teachers' view is consistent with Hao's (2016) opinion that transformation of teacher for a quality education 
system demands creative and innovative strategies to empower pre-service teachers for the future classrooms.

\section{Seamless Learning}

The ability to continue learning across various situation and scenario mediated by the mobile application is considered seamless learning. It is considered as an important skill in the $21^{\text {st }}$ century learning. Students importantly pointed out that:

With this usage of WhatsApp in our learning progress, we don't have to wait to enter the class to study. We can freely study anytime, anywhere as when a question or discussion has been posted we can take time and share answers when are ready to answer (PS12).

Meaningful interactions beyond the conventional classroom settings allow the pre-service teachers share, discuss and reflect on what they have learned. WhatsApp can unearth the learners from formal classrooms and give opportunity for learning in an expanded variety of settings, times and ways. One of them stated:

We could have discussion at any place without the need to be together at the same time. Links and information can be shared, read and feedback can be given immediately. I can also check back previous messages for clearance when I am lost (PS11)

WhatsApp is able to steer away from didactic classroom approach to a more conducive and flexible environment. This was exemplified in the following comment of the pre-service teacher:

Yes. $i$ find it hard to interact with all those formalities. Rather stiff If I had to say informalities made it easier to accept other's opinion and compare it with mine in order to produce something more quality

(PS 7)

The flexibility of time and space has been highlighted by the participants. One of them reported that:

'I always do my work on the last minute. With this environment, I can choose whenever I want to answer as long as it's not beyond the deadline. Next, I find it rather easy to review me" (PS 8). 
This is very likely that mobile learning bridges informal and formal education (Mills, Knezek \& Khaddze (2014). In fact, Sharples et al. (2009) highlighted that technologies in education give way to new methodological strategies which contribute to the opening of schools to the outside world. Further, technologies create better interactions between schools and families and between teachers and students which permit teachers to facilitate students. There are possibilities that seamless learning is going to be the future of learning. This is in line with several studies, indicating that mobile technology has opened up opportunities for seamless learning (Wong, Mildrad \& Speecht, 2013).

\section{Teaching and Learning support}

The pre-service teachers were contented with the flexibility of WhatsApp. They were able to access relevant materials at different time and place, creating opportunities for learning. According to one of the pre-service teachers:

What App allows quick and easy transfer of materials and web-resources. Discussion can be at any time convenient to learners. Such facilities are significant in today's learning scenario (PS2)

Pre-service teacher had someone who they can ask questions, discuss and collaborate to complete their tasks. They were able to collect and recall the course materials more efficiently and effectively. PS4 revealed that:

We could have discussion at any place without need to be together at the same time. Links and information can be shared, read and feedback can be given immediately. I can also check back previous messages for clearance when I am lost in the discussion or when I am late to be online

I am able to present my ideas in a more variety sentence structures. Besides that, I am able to use more vocabulary when I was paraphrasing the text I found from Internet to avoid plagiarism.

In sum, the WhatsApp enhances learning and scaffolding is available with a wide range of online resources through which the pre-service 
teachers get assistance. This study identified findings that is parallel to Hannafin and Land's (1997) view that scaffolding not necessarily limited to students-student and teacher-student interactions. In fact, Hannafin and Land asserted that technology environment offer scaffolding and resources to encourage personal and individual reflection.

\section{Extended Interactions Space}

Traditional classroom learning is a one-way process which is very often meant to disseminate knowledge rather than improve interactions between student-teacher, teacher- student and studentcontent. In this study, the interactions were pertinent in knowledge construction and to mould pre-service teachers towards educational technologies. For example:

Internet interaction helps me in my learning process as we can respond to each other without hesitation and or disagreement and be seen via Internet. We can include to support our statements as anything can be searched through Internet... (PS10)

One of them commented that:

I find it hard to interact with all those formalities. Rather stiff if I had to say. Informalities made it easier to accept other's opinion and you don't feel awkward or limited to express your opinions (PS6)

This study supports previous studies (Anduyar \& Cruz, 2017; Appiah, 2016; Bouhnik \& Deshen, 2014; Aharony, 2014) that using WhatsApp for learning purposes improve students' interactions. The pre-service teachers experience is in accordance to the constructivist learning theory that emphasized interactions where learners are to produce knowledge rather than consume knowledge (Shen \& Suwanthep, 2011).

\section{Technical Problems}

While the general experience of WhatsApp was an appositive one, unpleasant experiences were also highlighted. Both lecturers have no difficulties in using the WhatsApp for educational purpose but the pre-service teachers had connectivity difficulties namely readability, conversational structure, physical appearance, limited 
input capability, Internet speed and short battery life. For example,

I don't have my mobile data everytime I use my phone. So, I find it hard to communicate online especially when I work with it. My phone's battery sometimes failed me... I didn't even finished typing and it shut itself down” (PS5).

Moreover, pre-service teachers were not having their allowance and it was a financial burden for them. They explained:

The disadvantage is phone bill. I'm a student so I know how harsh an Internet plan do to a student. I do have an allowance. But the allowance was not meant for something else like foods, books and etc (PS6).

Sometimes Internet connection might be weak and feedback couldn't be given immediately.... The responses might be delayed. Online learning is a little time consuming because we need to wait for the others respond first before proceeding to a different topic. occur when wanting to upload when wanting to upload or download different forms of media shared in group (PS6).

Technical problems delayed their interactions and negotiations with their peers. This corresponds with other online learning environment studies (Goldstein \& Peled 2016; Annamalai, 2015) that highlighted technical problems when students work on the online learning environment. The positive and negative themes are illustrated in Table 1.

Table 1

\section{Positive Themes Negative Theme}

Teaching and Learning Approach

Technical Problem

Bite Size Learning

$21^{\text {st }}$ Century Learning

Seamless Learning

Teaching and Learning Support

Extended Interactions Space 


\section{CONCLUSION}

The findings of this study underscore the strength of WhatsApp as a worthwhile educational platform. This study meant to advance the understanding of WhatsApp as a learning platform and strategies that can be considered to improve teaching and learning activities. It has allowed a number of positive pedagogical shift mainly form isolated learning environment to social learning environment and from text based materials to multimedia materials. The easy use of technologies in a way helps to orientate their interests in the use of technology in the pedagogical practices. WhatsApp appeared as a platform for self-directed learning, active engagement in learning and creation of meaningful and worthwhile product. Social constructivism and situated learning for meaningful teaching and learning activities are possible with WhatsApp. In fact, WhatsApp has allowed knowledge construction rather than reproduction; (b) conversation rather than reception; (c) articulation rather than repetition; (d) collaboration rather than competition; and reflection rather than prescription as suggested by Keengwe et al. (2008, p.86).

The main issue emerging from these themes is that students were only directed for discussion and the instructors were not keen to interact with students in the WhatsApp platform for scaffolding. The importance of teacher presence (lecturer in this research) is pertinent to further enhance the discussion. However, the lecturers were completely missing on the WhatsApp platform. Intervention by the lecturers should include discussion related to content, techniques of answering questions and constructive feedback for students to further work on certain ideas. The prospective teachers should also be provided with a model on how they should play a crucial role when technology is integrated in pedagogical practices. Sipila (2014) highlighted that teachers' digital competency influences the use of ICT tools in teaching and learning activities. Similarly, Luan et al. (2006) cautioned that if technological, pedagogical and content knowledge (TPACK) are not instilled during pre-service education, prospective teachers will not be keen to integrate such approach in their teaching in future. TPACK as suggested by Koehler and Mishra (2009) is an important conduit for teachers to design effective pedagogical practices.

Pre-service teachers need to realize the pedagogical organization that works best with technologies. Katic (2008, p. 178) highlighted that: 
What pre-service teachers need to practice is not pregiven applications, but their own research and meaning making skills in discovering what pedagogical methods appeal to them and how technological advances could enhance their preferred practices. It is not the application of some technological knowledge that is important, rather it is the exploration of learning objectives...

Overall the paper adds to the growing body of research of related work on how WhatsApp can be used in educational context. The purpose of this small scale study is to provide a deeper understanding of WhatsApp and how the positive experiences can be utilized for educational contexts and how the problems highlighted can be minimized.

Further, it appears that WhatsApp was never used as a platform for assessment in this study and the traditional classroom assessment was prioritized. In fact, teachers can suggest students to video their micro teaching and upload it in WhatsApp. Online quizzes can also be conducted. WhatsApp can be used to upload many other assessment activities.

In conclusion, the use of WhatsApp for teaching and learning activities can enhance the learning achievements. Some technical problems were discussed. Nevertheless, the overall positive experience of WhatsApp as an educational platform was encouraging. As this is a small scale study to provide a picture of just 12 students in a class, this research contains certain limitations. The glaring drawback is the lack of generalizability. Therefore, clear conclusions are not possible. Nevertheless, this study makes important strides in expanding our understanding of what is expected in the use of WhatsApp as a learning platform. The study should be carried out with larger sample and should also include participants from other disciplines too. Mixed method analysis should also be considered to have a comprehensive, in-depth understanding of WhatsApp. Future studies should also involve the investigation related to interaction in WhatsApp. Overall, it can be concluded that the combination of WhatsApp and appropriate pedagogical practices will represent viable and effective EFL teaching and learning activities in future. 


\section{ACKNOWLEDGEMENT}

The research reported in this article was funded by Universiti Sains Malaysia Short Term Grant 304/PJJAUH/6313208.

\section{REFERENCES}

Aharony, N. (2015). Why do students use What's App? An exploratory study. Aslib Journal of Information Management, 67(2), 136-158.

Annamalai, N., Tan Kok Eng, Abdullah, A., \& Sivagurunathan, S. (2015). Exploring the Interactions on an online narrative writing platform. Malaysian Journal of Learning and Instruction, 12 (2015), 103-129.

Appiah, M. K. (2016). Influence of Whatsapp on study habit of university students in Ghana. International Journal of Research in Economics and Social Sciences, 6(3), 280-292.

Andújar-V. A., \& Cruz-M. M. S. (2017). Mobile instant messaging: Whatsapp and its potential to develop oral skills. Comunicar, 25(50), 43-52.

Bouhnik,D.,\& Deshen,M.(2014). WhatsApp goes to school: Mobile instant messaging between teachers and students. Journal of Information Technology Education: Research, 13, 217-231.

Braun, V., \& Clarke, V. (2006). Using thematic analysis in psychology. Qualitative research in psychology, 3(2), 77101.

Costa, P. T., \& McCrae, R. R. (1992). Four ways five factors are basic. Personality and individual differences, 13(6), 653665.

Creswell, J. W., \& Poth, C. N. (2017). Qualitative inquiry and research design: Choosing among five approaches. Sage publications.

Davis, F. D. (1989). Perceived usefulness, perceived ease of use, and user acceptance of information technology. MIS Quarterly, 319-340.

Fattah, S. F. E. S. A. (2015). The effectiveness of using whatsapp messenger as one of mobile learning techniques to develop students' writing skills. Journal of Education and Practice, 6(32), 115-127.

Goldstein, O., \& Peled, Y. (2016). Pedagogical aspects of integrating teacher education. Technology, Pedagogy and Education, 25(4), 469-486. 
Hannafin, M. J., \& Land, S. M. (1997). The foundations and assumptions of technology-enhanced student-centered learning environments. Instructional Science, 25(3), 167202.

Hani, N. A. B. (2014). The Impact of whats app group's utilization on EFL vocabulary writing amelioration. International Journal of University Teaching and Faculty Development, 5(2), 7387.

Hao, Y. (2016). The development of pre-service teachers' knowledge: A contemplative approach. Computers in Human Behavior, 60, 155-164.

Haydn, T. A., \& Barton, R. (2007). Common needs and different agendas: How trainee teachers make progress in their ability to use ICT in subject teaching. Some lessons from the UK. Computers \& Education, 49(4), 1018-1036.

Jones, A. C., Scanlon, E., \& Clough, G. (2013). Mobile learning: Two case studies of supporting inquiry learning in informal and semiformal settings. Computers \& Education, 61, 21-32.

Katić,E.K.(2008).Preservice teachers' conceptions aboutcomputers: An ongoing search for transformative appropriations of modern technologies. Teachers and Teaching: theory and practice, 14(2), 157-179.

Katz, E. (1959). Mass communications research and the study of popular culture: An editorial note on a possible future for this journal. Studies in Public Communication, 2, 1.

Keengwe, J., Onchwari, G., \& Wachira, P. (2008). Computer technology integration and student learning: Barriers and promise. Journal of Science Education and Technology, 17(6), 560-565.

Koehler, M., \& Mishra, P. (2009). What is technological pedagogical content knowledge (TPACK)?. Contemporary issues in technology and teacher education, 9(1), 60-70.

Korthagen, F., Loughran, J., \& Russell, T. (2006). Developing fundamental principles for teacher education programs and practices. Teaching and teacher education, 22(8), 10201041.

Leidner, D. E., \& Jarvenpaa, S. L. (1995). The use of information technology to enhance management school education: A theoretical view. MIS quarterly, 265-291.

Luan, W. S., Bakar, K. A., \& Hong, T. S. (2006). Using a studentcentred learning approach to teach a discrete information technology course: the effects on Malaysian pre service 
teachers' attitudes toward information technology.Technology, Pedagogy and Education, 15(2), 223-238.

Man, C. K. (2014). Word's up with WhatsApp: the use of instant messaging in consciousness-raising of academic vocabulary. In 23rd MELTA and 12th Asia TEFL International Conference (pp. 28-30).

Mills, L.A., Knezek, G., \& Khaddage, F. (2014). Information seeking, information sharing, and going mobile: Three bridges to informal learning. Computers in Human Behavior, 32, 324334.

Norris, C., \& Soloway, E. (2013). Substantive Educational Change is in the Palm of our Children's Hands. Retrieved from http:// cecs6030.pbworks.com/w/file/fetch/58073860/Book\%20 Chapter\%20Zane\%20Lin\%20Norris\%20Soloway\%20 FINAL.pdf

Sharples, M. (2013). Mobile learning: research, practice and challenges. Distance Education in China, 3(5), 5-11.

Sharples, M., Arnedillo-Sánchez, I., Milrad, M., \& Vavoula, G. (2009). Mobile learning. In Technology-enhanced learning (pp. 233-249). Springer, Dordrecht.

Shen, L., \& Suwanthep, J. (2011). E-learning Constructive Role Plays for EFL Learners in China's Tertiary Education. Online Submission, 49, 1-26.

Sipilä,K.(2014). Educational use of information and communications technology: Teachers' perspective. Technology, Pedagogy and Education, 23(2), 225-241.

Stahl, S. M., Davis, R. L., Kim, D. H., Lowe, N. G., Carlson, R. E., Fountain, K., \& Grady, M.

M. (2010). Play it again: The master psychopharmacology program as an example of interval learning in bite-sized portions. CNS spectrums, 15(8), 491-504.

Susilo, A. (2014). Exploring Facebook and Whatsapp as supporting social network applications for English learning in higher education.

The Statistical Portal (2017). Retrieved from www.statista.com/ statistics/260819/number-of-monthly-active-whatsapp-users. Accessed

Tondeur, J., van Braak, J., Ertmer, P. A., \& Ottenbreit-Leftwich, A. (2017). Understanding the relationship between teachers' pedagogical beliefs and technology use in education: A systematic review of qualitative evidence. Educational Technology Research and Development, 65(3), 555-575. 
Vygotsky, L. S. (1997). The collected works of LS Vygotsky: Problems of the theory and history of psychology (Vol. 3). Springer Science \& Business Media.

Wong, L. H., Milrad, M., \& Specht, M. (Eds.). (2015). Seamless learning in the age of mobile connectivity. Singapore: Springer.

Wong, L. H. (2013). Enculturating self-directed learners through a facilitated seamless learning process framework. Technology, Pedagogy and Education, 22(3), 319-338.

Yeboah,J.,\& Ewur, G.D.(2014). The impact of WhatsApp messenger usage on students' performance in Tertiary Institutions in Ghana. Journal of Education and Practice, 5(6), 157-164. 